\title{
TRABAJADORES MIGRANTES Y SEGURIDAD SOCIAL: APROXIMACIÓN NACIONAL E INTERNACIONAL A LOS MECANISMOS DE PROTECCIÓN QUE OTORGAN CONTINUIDAD A LAS PRESTACIONES
}

\author{
II PARTE \\ Pablo Arellano Ortiz* \\ Universidad Austral de Chile
}

\begin{abstract}
RESUMEN: Este trabajo desarrolla el problema de las migraciones y su relación con la protección de la seguridad social al trabajador migrante. De esta manera, se intenta dar una visión global a este problema. En primer lugar, se desarrollarán algunos aspectos conceptuales que se consideran necesarios para la compresión del trabajo, tales como: trabajador migrante y coordinación. En un segundo lugar, se estudia cuáles son las normas internacionales relativas a la problemática en cuestión. Así se hace referencia a las normas sobre derechos humanos relativas al tema y además se hace un particular análisis de las normas de la OIT, y los principios que emanan de estas. En un tercer lugar se analizará la normativa nacional. Se estudiará y categorizará los distintos acuerdos bilaterales vigentes sobre la materia para luego hacer una referencia al Convenio Multilateral Iberoamericano de Seguridad Social. En este acápite se realiza una evaluación de la legislación nacional sobre migraciones y seguridad social. El trabajo termina con una serie de conclusiones en relación a la normativa tanto nacional como internacional sobre la protección de seguridad social que se debe entregar al trabajador migrante.
\end{abstract}

Palabras clave: Seguridad social, trabajador migrante, coordinación, acuerdos bilaterales.

ABSTRACT: This paper develops the problem of migration and its relationship with the social security protection of migrant workers. In this way, we try to give an overview of this problem. First,we will develop some conceptual aspects that are considered necessary for the understanding of work, such as migrant workers and coordination. Second, we study what are the international standards for the issue in question. This refers to human rights standards relating to the subject and also takes a special analysis of ILO standards and the principles that flow from these. Third, we analyze national regulations. We will study and categorize the various bilateral agreements on the subject and then make a reference to the Latin American Multilateral Agreement on Social Security. This section will provide an evaluation of the national legislation on migration and social security. The paper ends with some conclusions in relation to national and international standards on the protection of social security to be delivered to the migrant worker.

Key words: Social security, migrant worker, coordination, bilateral agreements.

\footnotetext{
* Profesor de Derecho del Trabajo y de Seguridad Social, Universidad Austral de Chile. Doctor en Derecho, Université Paris Ouest Nanterre La Defense, France; Master 2 Recherche Droit Social et Droit de la Santé, Université de Paris X Nanterre, France; Master 2 Recherche Droit Social de la Université de Paris II Panthéon Assas, France. Abogado, Universidad de Concepción, Chile. Dirección postal: Universidad Austral de Chile, Facultad de Ciencias Jurídicas y Sociales, Campus Isla Teja S/N, Valdivia, Chile. Email: pablo. arellano@uach.cl

Este trabajo forma parte de los proyectos Fondecyt Iniciación N 11121677, “La coordinación de sistemas de seguridad social: Estudio comparado Unión Europea e Iberoamérica” y del Proyecto DID No S-2012-44 Universidad Austral de Chile, "Los mecanismos de coordinación de sistemas de seguridad social: Europa e Iberoamérica”. La primera parte de este trabajo fue publicada en la Revista Chilena de Derecho del Trabajo, vol. 3, no 6, 2012, Santiago, Chile, pp. 87-109.
} 


\section{COMO RECOGE CHILE LA PROTECCIÓN DE SEGURIDAD SOCIAL DEL TRABAJADOR MIGRANTE}

Una vez revisada la protección que se otorga a nivel internacional al migrante, y en particular enfocados a la seguridad social, pasaremos a estudiar la situación chilena. Para poder saber cómo se le entrega protección de seguridad social al migrante en nuestro país, dividiremos nuestro análisis en dos grandes aristas: una internacional y una nacional. Esta división nos llevará por el estudio de los instrumentos internacionales enunciados en la primera parte, tanto bilaterales como multilaterales, para luego referirnos a la legislación interna.

\subsection{LOS CONVENIOS BILATERALES DE SEGURIDAD SOCIAL}

La situación precaria de los trabajadores migrantes y su relación con la seguridad social formal se puede resumir como un asunto que compete a la legislación nacional ${ }^{1}$. De esta manera, el país de acogida regula los beneficios a los que los migrantes tienen acceso y las condiciones bajo las que tienen acceso. Sin embargo, aun cuando la legislación nacional prescriba que se tiene que aplicar por igual, la protección para los trabajadores migrantes puede estar limitada. Esto tiene que ver con la aplicación de la ley, pero también con el alto porcentaje de migrantes que ejercen labores dentro de la economía informal.

Los acuerdos bilaterales tienen por objeto entregar una continuidad en la cobertura al conectar dos legislaciones. En este proceso, en general, no se intercambian dineros sino que más bien se reconocen periodos de afiliación o de cotización que permitan al migrante poder cumplir con los requisitos necesarios para tener derecho a una prestación. Dentro de este marco, el convenio de seguridad social firmado entre Chile y Perú en 2002 es una excepción puesto que ambos sistemas de pensiones se basan en cuentas individuales de capitalización individual. Dicho convenio reconoce el derecho de los trabajadores de transferir el saldo acumulado de la cuenta de capitalización individual de una parte contratante a la otra, de modo que los fondos pueden ser manejados en una sola cuenta por la AFP privada elegida por el trabajador².

Antes de analizar los convenios de seguridad social firmados por nuestro país haremos una breve referencia a los objetivos que dichos instrumentos deben cumplir.

\subsubsection{De los convenios bilaterales en general}

Los propósitos de los convenios de seguridad social se pueden sintetizar en dos propósitos principales ${ }^{3}$. Primero, los convenios ayudan a mantener la continuidad en la cobertura en la seguridad social para los trabajadores que han dividido sus carreras entre dos países, al permitir que el trabajador califique para beneficios parciales en ambos sistemas de seguridad social con base en la totalización de los periodos de contribución en ambos países. En segundo lugar, eliminan la doble tributación de la seguridad social, situación que ocurre cuando un trabajador de un país trabaja en otro país y requiere pagar contribuciones de seguridad social a ambos países por el mismo trabajo.

\footnotetext{
SABATES-Wheeler Rachel; KoetTl, Johannes. "Protección social para los migrantes: los desafíos de la prestación en el contexto del cambio en los flujos migratorios", en: Revista Internacional de Seguridad Social, vol. 63, 3-4/2010, p. 135.

Conferencia Interamericana de Seguridad Social. Informe sobre la Seguridad Social en América 2006. Los Retos del Envejecimiento y la Discapacidad: Empleo y Aseguramiento, Convenios Internacionales de Seguridad Social, Conferencia Interamericana de Seguridad Social, edición 2006; Capítulo 4: Convenios Internacionales de Seguridad Social, p. 93.

$3 \quad$ Ibid., p, 91.
} 
Por otro lado, se ha señalado que la protección social para migrantes internacionales consiste en cuatro componentes ${ }^{4}$ :

a) Acceso a la protección social formal -es decir, seguridad social y servicios sociales- en los países de acogida y de origen;

b) Subrogabilidad de los derechos adquiridos a la seguridad social entre los países de acogida y de origen;

c) Condiciones del mercado de trabajo para los migrantes en los países de acogida y proceso de reclutamiento de los migrantes en el país de origen, $\mathrm{y}$

d) Acceso a las redes informales para apoyar a los migrantes y sus familiares.

Estos propósitos y componentes permiten entregarle al trabajador migrante una efectiva protección de seguridad social, aunque descartamos la letra c) como parte integrante de la protección de seguridad social por no decir relación con esta. Entonces, el resto de estos objetivos permiten cumplir con el derecho humano que este tiene a la cobertura de seguridad social. Compartimos la afirmación que enuncia que los convenios de seguridad social constituyen actualmente la «mejor práctica» respecto a cómo coordinar el acceso y permitir la subrogabilidad de prestaciones de la seguridad social para los migrantes ${ }^{5}$.

Sin embargo, la mayoría de los acuerdos se refieren a prestaciones de larga duración, como las pensiones de vejez, invalidez y sobrevivientes, así como otras pensiones vitalicias. Las prestaciones de asistencia médica son objeto de los acuerdos de seguridad social en una medida mucho menor. Generalmente, las prestaciones financiadas con impuestos están explícitamente excluidas. Entonces cabe preguntarse sobre el verdadero efecto de estos convenios en su intento de igualar las condiciones de nacionales y extranjeros.

\subsubsection{Convenios bilaterales firmados por Chile}

La Superintendencia de Pensiones ha definido a los convenios bilaterales de seguridad social como:

"En términos generales, los Convenios Bilaterales de Pensiones, o Convenios de Seguridad Social, suscritos por Chile, permiten a los afiliados al Sistema de Administradoras de Fondos de Pensiones, chilenos o extranjeros, que registren cotizaciones tanto en Chile como en el otro Estado Contratante, obtener pensiones paralelas en ambos países, utilizando la totalización de períodos de seguro cuando ello sea necesario".

Los criterios que la Superintendencia de Pensiones dicen relación con el sistema de capitalización individual y con la posibilidad de totalizar periodos tomando en cuenta cotizaciones efectuadas en más de un país. Dichos criterios nos parecen restrictivos en relación al alcance de estos convenios y además en vista de los convenios firmados por nuestro país.

Dentro de la seguridad social chilena los convenios bilaterales no han tenido un desarrollo por la doctrina, siendo las referencias a este tipo de instrumentos más bien escasas ${ }^{6}$. Debemos, eso

SAbates-Wheeler Rachel; KoetTL, Johannes, op. cit. (n. 1), p. 131.

Sabates-Wheeler Rachel; Koettl, Johannes, op. cit. (n. 1), p. 138.

Cifuentes Lillo, Hugo. "Tratados internacionales de seguridad social: Convenios bilaterales", en: Estudios en Homenaje al 
sí, notar que con la vuelta a la democracia nuestro país realizó esfuerzos importantes para crear una red de acuerdos bilaterales que permitieran una continuidad en la protección de seguridad social. Esto se puede comprobar fácilmente si nos fijamos en las fechas de suscripción de los instrumentos.

\begin{tabular}{|l|l|}
\hline \multicolumn{1}{|c|}{ País } & \multicolumn{1}{c|}{ Fecha (suscripción) } \\
\hline Alemania & 5 de marzo de 1993 \\
\hline Argentina & 26 de abril de 1996 \\
\hline Australia & 25 de marzo de 2003 \\
\hline Austria & 19 de junio de 1997 \\
\hline Bélgica & 9 de septiembre de 1996 \\
\hline Brasil & 16 de octubre de 1993 \\
\hline Canadá & 18 de noviembre de 1996 \\
\hline Colombia & 9 de diciembre de 2003 \\
\hline Dinamarca & 8 de marzo de 1995 \\
\hline Ecuador & 23 de enero de 2006 \\
\hline España & 28 de enero de 1997 \\
\hline Estados Unidos & 16 de febrero de 2000 \\
\hline Finlandia & 7 de marzo de 1997 \\
\hline Francia & 25 de junio de 1999 \\
\hline Holanda & 10 de enero de 2006 \\
\hline Luxemburgo & 3 de junio de 1997 \\
\hline Noruega & 3 de abril de 1997 \\
\hline Perú & 23 de agosto de 2002 \\
\hline Portugal & 25 de marzo de 1999 \\
\hline Québec & 21 de febrero de 1997 \\
\hline República Checa & 7 de diciembre de 2000 \\
\hline Suecia & 13 de marzo de 1995 \\
\hline Suiza & 20 de junio de 1996 \\
\hline Uruguay & 1 de agosto de 1997 \\
\hline Venezuela & \\
\hline Dibril de 2005 \\
\hline
\end{tabular}

Fuente: Elaboración propia a partir de la información disponible en www.spensiones.cl 
De este listado de convenios bilaterales debemos señalar que no todos se encuentran vigentes y en aplicación, aquellos que se encuentran en vigor y que obligan nuestro país son los firmados con: Alemania, Argentina, Australia, Austria, Bélgica, Canadá (y además uno específico con Quebec), Dinamarca, Ecuador, Estados Unidos de Norteamérica, España, Finlandia, Francia, Holanda, Luxemburgo, Noruega, Perú, Portugal, República Checa, Suiza, Suecia y Uruguay. A este grupo debemos agregar el Convenio Multilateral Iberoamericano de Seguridad Social en vigor desde el 1 de mayo de 2011. Además, se encuentran firmados por nuestro país acuerdos bilaterales con Venezuela y Colombia, pero dichos instrumentos aún no entran en vigencia. Debemos señalar también que han existido negociaciones con otros países pero por razones que desconocemos no se ha logrado firmar el convenio bilateral, tal sería el caso del intento de convenio bilateral con Costa Rica.

Por otro lado, podemos establecer ciertas clasificaciones aplicables a los convenios bilaterales suscritos por Chile. Así, en cuanto al ámbito material, se puede señalar que en su gran mayoría estos no cubren todos los riesgos de la seguridad social, limitándose a la vejez, invalidez y sobrevivencia. Sin embargo existe un grupo pequeño que cubre el riesgo salud, dentro de este grupo encontramos, por ejemplo, el convenio bilateral con Francia.

Como ya lo enunciamos también en nuestro país se pueden clasificar los convenios según el mecanismo que posean para realizar la totalización de periodos. Así, por un lado, encontramos el convenio bilateral firmado con Perú que permite la transferencia de fondos, ya que en ambos países el mecanismo de la capitalización individual existe al mismo nivel, y se acordó expresamente esta transferencia. Por otro lado, en los demás convenios se ha establecido lo que hoy en día es la regla general a nivel internacional, que es el reconocimiento proporcional pero sin transferencia de dineros. Se reconoce lo cotizado en el otro país pero no se intercambia dinero.

Finalmente, debemos afirmar que la coordinación de un sistema de seguridad social con el de otro país resulta difícil, vistos los convenios bilaterales firmados por nuestro país. Se articulan riesgos más que un sistema. Lo más cercano a una coordinación sistémica, lo constituye el Convenio Multilateral Iberoamericano de Seguridad Social aunque este también posee ciertas limitaciones.

\subsection{El Convenio Multilateral Iberoamericano de Seguridad Social}

Dentro de la evolución de los instrumentos internacionales, encontramos este instrumento que se presenta como una solución de largo plazo a la cobertura de seguridad social para migrantes dentro de la región. El origen del Convenio Multilateral Iberoamericano de Seguridad Social lo podemos encontrar en la V Conferencia de Ministros y Máximos Responsables de Seguridad Social de los países de Iberoamérica, celebrada en Segovia (España), en el año 2005, y en los acuerdos surgidos de la XV y XVI Cumbres Iberoamericanas de Jefes de Estado y de Gobierno, que condujeron a la aprobación del texto definitivo del Convenio Multilateral por parte de los Jefes de Estado y de Gobierno en la XVII Cumbre Iberoamericana de Santiago de Chile, en noviembre de 2007.

En el año 2009, en las reuniones de Lisboa, se dio vía libre al contenido del Acuerdo de Aplicación. Dicho acuerdo resulta importante para la determinación de la entrada en vigor efectiva del Convenio. En el momento actual, el Convenio ha sido ratificado por Argentina, Brasil, Bolivia, Chile, Ecuador, El Salvador, España, Paraguay, Portugal, Uruguay y Venezuela. El convenio ha entrado habiendo entrado en vigor el 1 de mayo de 2011, correspondiendo al primer día del tercer mes siguiente a la fecha en que se haya depositado el séptimo instrumento de ratificación, aceptación, aprobación o adhesión. Sin embargo, para aplicación efectiva es necesario que los paí- 
ses hayan suscrito el Acuerdo de Aplicación. De esta manera el Convenio es plenamente efectivo en Bolivia, Brasil, Chile, Ecuador, El Salvador, España, Portugal, Paraguay y Uruguay. La plena eficacia en el resto de los países dependerá de la pronta suscripción del Acuerdo de Aplicación.

\begin{tabular}{|c|c|c|c|c|c|c|}
\hline $\begin{array}{l}\text { PAISES OUE LO } \\
\text { HAN FIRMADO }\end{array}$ & $\begin{array}{l}\text { FECHA } \\
\text { FIRMA } \\
\text { CONVENIO }\end{array}$ & $\begin{array}{l}\text { FECHA } \\
\text { RATIFICACION }\end{array}$ & $\begin{array}{c}\text { ГECHA } \\
\text { DEPOSITO } \\
\text { INSTRUMENTO } \\
\text { RATIFICACION EN } \\
\text { LA SECIB-OISS }\end{array}$ & $\begin{array}{l}\text { FECHA } \\
\text { SUSCRIPCION } \\
\text { ACUERDO } \\
\text { APLICACION }\end{array}$ & $\begin{array}{l}\text { APLICACION } \\
\text { EFECTIVA } \\
\text { CONVENIO }\end{array}$ & POBLACION DI \\
\hline Argentina & $10 / 11 / 2007$ & 09/06/2010 & & & & \\
\hline${ }^{2}$ Bolivia & $10 / 11 / 2007$ & $03 / 11 / 2010$ & $02 / 02 / 2011$ & $18 / 04 / 2011$ & $x$ & 10.426 .160 \\
\hline Brasil & $10 / 11 / 2007$ & $30 / 10 / 2009$ & $11 / 12 / 2009$ & $19 / 05 / 2011$ & $x$ & 190.755 .799 \\
\hline Chile & $10 / 11 / 2007$ & $18 / 11 / 2009$ & $30 / 11 / 2009$ & $01 / 09 / 2011$ & $x$ & 17.094 .275 \\
\hline Colombia & $26 / 11 / 2008$ & & & & & \\
\hline Costa Rica & $10 / 11 / 2007$ & & & & & \\
\hline Ecuador & $07 / 104 / 2008$ & $31 / 08 / 2009$ & $04 / 11 / 2009$ & $20 / 06 / 2011$ & $x$ & 14.306.876 \\
\hline El Salvador & $10 / 11 / 2007$ & $29 / 05 / 2008$ & $04 / 09 / 2008$ & $17 / 11 / 2012$ & $\mathbf{x}$ & 6.251 .495 \\
\hline España & $10 / 11 / 2007$ & $05 / 02 / 2010$ & $12 / 02 / 2010$ & $13 / 10 / 2010$ & $x$ & 47.021 .031 \\
\hline Paraguay & $10 / 11 / 2007$ & $15 / 12 / 12010$ & $09 / 02 / 2011$ & 28/10/2011 & $x$ & 6.391 .000 \\
\hline Perú & $10 / 11 / 2007$ & & & & & \\
\hline Portugal * & $10 / 11 / 2007$ & $27 / 10 / 2010$ & $22 / 12 / 2010$ & $19 / 03 / 2013$ & $x$ & 11.400 .000 \\
\hline República Dominicana & $07 / 10 / 2011$ & & & & & \\
\hline$\stackrel{\text { a }}{=}$ Uruguay & $10 / 11 / 2007$ & $24 / 05 / 2011$ & $26 / 07 / 2011$ & 26/07/2011 & $x$ & 3.356 .584 \\
\hline Venezuela & $10 / 11 / 2007$ & $16 / 02 / 2009$ & & & & \\
\hline
\end{tabular}

Fuente: www.oiss.org visitado el 2 de junio de 2013 a las 8:10 am.

En el caso del Convenio Multilateral Iberoamericano posee, tal como en la UE, un sistema de prorrata, pero además en el Capítulo 2 denominado "Coordinación de regímenes y legislaciones basados en el ahorro y la capitalización", se refiere, como su nombre lo indica, al problema que se presenta en Europa con la apertura hacia el Este. Se regula la situación de un régimen obligatorio, de la prestación mínima garantizada y de un régimen voluntario. Además, se señala expresamente que podrán establecerse mecanismos de transferencia de fondos a los fines de la percepción de prestaciones por invalidez, vejez o muerte.

Sin lugar a dudas, el proceso iberoamericano se ha visto fuertemente influenciado por la experiencia europea. Así, por ejemplo, Sánchez-Rodas nos recuerda que la redacción de su articulado se asemeja bastante e incluso se mejora ${ }^{7}$. Debemos señalar que el contenido del Convenio Multilateral Iberoamericano de Seguridad Social es el fruto del esfuerzo y de la colaboración de los representantes de todos los países y la colaboración técnica de la Organización Iberoamericana de Seguridad Social.

La normativa europea no se ha propuesto instaurar una política de uniformización de la seguridad social de los distintos estados comunitarios, ni siquiera contempla la posibilidad de alcanzar la armonización de políticas y legislaciones, se busca tan sólo coordinar los diversos sistemas de protección creados a nivel estatal de seguridad social público. Esta opción tomada por la región europea no fue al azar y responde a una decisión política regional que permite que los sistemas propios de cada país puedan subsistir.

Don Adolfo Jiménez, Secretario General de la OISS, grafica esta situación de la siguiente manera:

SÁnCHEZ-RodAS, C. "El Convenio Multilateral Iberoamericano de seguridad Social”, en: IUSTEL, junio 2011. 
"Cabe señalar que el Convenio Multilateral Iberoamericano, que coordina pero no modifica ni sustituye las legislaciones nacionales, constituye una experiencia inédita porque supone un acuerdo en materia de Seguridad Social entre Estados con modelos muy distintos, en un ámbito en el que no existe una previa asociación política que facilite el sustrato jurídico que podría darle apoyo, razón por lo que ha exigido la participación de todas y cada una de las partes, y su ratificación -o adhesión- precisa la incorporación como legislación interna de cada uno de los Estados"8.

\subsection{EVALUACiÓn DEL ORDENAMIENTO JURÍDICO CHILENO}

Estudiar una legislación implica ver como ésta trata al extranjero. Al respecto dos aspectos son imprescindibles de analizar. Por un lado, se debe verificar si el trabajador migrante recibe o no el mismo trato que el nacional, tanto al afiliarse como al recibir prestaciones. Y por otro lado, se debe estudiar cuales son las condiciones de empleabilidad que le permitan tener acceso a prestaciones.

La Dirección del Trabajo en relación a los trabajadores migrantes ha señalado, en el Dictamen Ord. N 5848/386 de 26 de noviembre de 1998, lo siguiente:

"La migración de trabajadores es una realidad del mundo contemporáneo que no sólo afecta a Chile sino que se extiende a todos los países que alcanzan un nivel de prosperidad y desarrollo superior al de sus países vecinos.

Ahora bien, tal como Uds. lo señalan, el hecho que un trabajador no tenga la nacionalidad chilena no autoriza para que se violen las normas laborales y previsionales, las cuales rigen por igual para todos los habitantes de la República, sean chilenos o extranjeros.

Ahondando lo anterior, debemos decir que nuestro ordenamiento jurídico excluye cualquier discriminación o preferencia basada en la nacionalidad del trabajador, salvo que así lo contemple expresamente la ley para casos determinados.

De consiguiente, si el trabajador extranjero presta sus servicios personales, intelectuales o materiales bajo subordinación y dependencia, el empleador está obligado a dar cumplimiento a todas las normas laborales vigentes, entre ellas, las de los artículos $9^{\circ}$ y 10 del Código del Trabajo, sin que tenga incidencia alguna la circunstancia de que el trabajador no reúna los requisitos de extranjería sobre residencia o permanencia legal.

Siguiendo este razonamiento, la Dirección del Trabajo, mediante circular No 113, de 16.07.98, ha establecido que en lo que se refiere al personal extranjero ya sea que esté o no autorizado para prestar servicios, se procede en los mismos términos que una fiscalización efectuada al personal chileno, respecto de contrato de trabajo, registro control de asistencia, jornadas, remuneraciones, descansos, etc., instruyéndose lo que corresponda y sancionándose todas y cada una de las infracciones que pudieran detectarse con arreglo a los procedimientos vigentes.

Respecto de la normativa previsional, los trabajadores extranjeros también se rigen en todo por la actual normativa vigente, debiendo seguirse los mismos procedimientos administrativos que se utilizan en una fiscalización de rutina.

Por lo tanto, ante cualquier situación de incumplimiento de las obligaciones laborales o previsionales que afecte a los trabajadores extranjeros, sea que estos cuenten o no con autorización para trabajar en el país, se debe realizar la denuncia o el reclamo correspondiente ante la Inspección del Trabajo, según los procedimientos generales".

Jiménez, A. "Una experiencia inédita", en: Miradas al Exterior. Revista de Información Diplomática del Ministerio de Asuntos Exteriores y de Cooperación, abril-junio 2011, n¹8, p. 19. 
El tratamiento del nuestra legislación en relación al migrante lo analizaremos partiendo por la consagración constitucional del principio de igualdad de trato para luego referirnos a la regulación de las condiciones laborales del trabajador migrante.

\subsubsection{Constitución de 1980}

Nuestra Constitución Política parte señalando en su artículo $1^{\circ}$ que las "Las personas nacen libres e iguales en dignidad y derechos". Al hacer esta declaración no se está haciendo ninguna distinción entre extranjeros y los nacionales chilenos. Considerándolos iguales.

Este principio de igualdad se explícita en el artículo 19, el cual enuncia las garantías constitucionales que la Constitución asegura a todas las personas. En particular en su número $2^{\circ}$ establece que "La igualdad ante la ley. En Chile no hay persona ni grupo privilegiados. En Chile no hay esclavos y el que pise su territorio queda libre. Hombres y mujeres son iguales ante la ley.

Ni la ley ni autoridad alguna podrán establecer diferencias arbitrarias".

Y en su número $3^{\circ}$ agrega que "La igual protección de la ley en el ejercicio de sus derechos"

A mayor abundamiento el número 16 establece "La libertad de trabajo y su protección.

Se prohíbe cualquiera discriminación que no se base en la capacidad o idoneidad personal, sin perjuicio de que la ley pueda exigir la nacionalidad chilena o límites de edad para determinados casos."

De las normas constitucionales expuestas se puede colegir que en Chile no procede ninguna discriminación o diferencia, garantizándose a los extranjeros la igualdad ante la ley. Todo extranjero en el territorio nacional debe ser tratado en la misma manera que un nacional. Tan solo en casos muy específicos se podría exigir la nacionalidad chilena para un determinado empleo.

Por su parte, el artículo $2^{\circ}$ del Código del Trabajo, en sus incisos $3^{\circ}$ y $4^{\circ}$, preceptúan:

"Son contrarios a los principios de las leyes laborales los actos de discriminación.

Los actos de discriminación son las distinciones, exclusiones o preferencias basadas en motivos de raza, color, edad, sexo, estado civil, sindicación, religión, opinión política, nacionalidad, ascendencia nacional u origen social, que tengan por objeto anular o alterar la igualdad de oportunidades o de trato en el empleo y la ocupación".

Debemos entender a estos incisos como una especificación en materia de derecho del trabajo del principio constitucional de no discriminación. Una suerte de legalización de normas constitucionales.

En este sentido la Dirección del Trabajo en el Dictamen Ord. N²628/040, de 1 de julio de 2009, ha señalado que "nuestro ordenamiento jurídico excluye cualquier discriminación o preferencia basada en la nacionalidad del trabajador, salvo que así lo contemple expresamente la ley para casos determinados".

En cuanto a los derechos fundamentales de los trabajadores migrantes, debemos recordar la noción de bloque de constitucionalidad en nuestro ordenamiento jurídico, a partir de lo dispuesto en el inciso 2 del artículo 5 de nuestra Carta. De esta manera, los trabajadores migrantes son igualmente protegidos por los instrumentos internacionales de derechos humanos. Pero a mayor abundamiento, y como ya lo hemos sostenido ${ }^{9}$, creemos que en nuestro país es posible por esta vía hacer exigible derechos contenidos en instrumentos sobre derechos humanos que nuestro

Vid. Arellano Ortiz, Pablo. "La conformidad de la legislación chilena a las normas internacionales del trabajo de la OIT", en: Revista de Derecho de la Universidad Católica de la Santísima Concepción, junio 2011, Concepción, Chile, ISSN 0717-0599, pp. 39-60 
país no ha ratificado. Lo que permitiría un mayor compromiso de nuestro país hacia los migrantes. Por ejemplo, podremos citar la norma sobre igualdad de trato contenida en el convenio 102 de la OIT. Convenio que nuestro Tribunal Constitucional ha citado como constitutivo de las bases de todo sistema de seguridad social, no obstante que no ha sido ratificado por nuestro país.

Entonces en relación a lo que se podría denominar Estatuto constitucional de los extranjero en nuestro país ${ }^{10}$, se reconoce al extranjero como persona y se le otorgan derechos basándose en el principio de igualdad y en el principio de no discriminación.

A este respecto resulta interesante la discusión sobre el domicilio como criterio de atribución de derechos ${ }^{11}$. Así, el domicilio político entregaría derechos emanados de la ciudadanía, por su parte, del domicilio civil entregaría derechos contenidos en el resto de la legislación, a saber, entrega competencia a tribunales, fija domicilio para efectos testamentarios, etc. Si bien compartimos la idea que el domicilio civil sirve como criterio para considerar al extranjero como integrante de la sociedad, nos resulta limitado debido a que en el caso de los extranjeros que ejercen trabajos en la economía informal resulta difícil atribuir dicho domicilio. Sin perjuicio de no tener domicilio, los derechos de estos trabajadores migrantes informales deben ser respetados.

\subsubsection{Legislación protectora en relación a los trabajadores extranjeros}

Antes de referirnos a la normativa del derecho del trabajo y de la seguridad social comenzaremos por las reglas relativas al ingreso de un trabajador a nuestro territorio. Dicha reglamentación se encuentra en el Decreto Ley $\mathrm{N}^{\circ} 1.094$, de 1975, que establece normas sobre extranjeros en Chile. Y que en los artículos 23 al 26 se refiere a los residentes sujetos a contrato. Determinándose que para que un extranjero pueda trabajar en Chile debe tener una visa que lo habilite para ello.

De esta manera, el artículo 23 del citado decreto señala que se otorgarán visaciones de residente sujetas a contrato, a los extranjeros que viajen al país con el objeto de dar cumplimiento a un contrato de trabajo. La misma visa se puede otorgar a los extranjeros que se encuentren en el territorio nacional y se radiquen en el país para dar cumplimiento a un contrato de trabajo. A igual visa tendrán derecho los miembros de la familia del extranjero. La visación sujeta a contrato tendrá una vigencia de hasta dos años y podrá ser prorrogada por períodos iguales. Si no se especifica plazo en el pasaporte, se entenderá que su vigencia es la máxima. Además, el extranjero residente sujeto a contrato podrá solicitar su permanencia definitiva al cumplir dos años de residencia.

Para solicitar la visa se debe acompañar un contrato de trabajo que deberá contener una cláusula por la que el empleador o patrón se comprometa a pagar el pasaje de regreso del trabajador y demás personas que estipule el contrato, según lo dispone el artículo 24.

La visa está condicionada a la existencia del contrato de trabajo. Por tanto, según el artículo 25 , la terminación del contrato que ha servido de antecedente para el otorgamiento de esta visa será causal de caducidad de ésta y deberá ser comunicada, dentro del plazo de 15 días, a la autoridad correspondiente, sin perjuicio del derecho de su titular a solicitar una nueva visación o la permanencia definitiva, si procediere.

Además, se establece en el artículo 26 la posibilidad que los artistas, deportistas y otros extranjeros debidamente calificados que ingresen al país y deseen desarrollar actividades remuneradas, se les conceda visa de residente sujeto a contrato.

\footnotetext{
10 Vid. ZúñIga Urbina, Francisco. "El estatus constitucional de extranjeros", en: Revista de Derecho, Universidad de Concepción, no 203, año LXVI, enero- junio, Concepción, Chile, 1998, pp. 301-330.

Vid. Segura Riveiro, Francisco, "Del domicilio político de los extranjero en Chile", en: Revista de Derecho, Universidad de Concepción, no 201, año LXV, enero-junio, Santiago, Chile, 1997, pp. 73-81.
} 
Por otro lado, y a mayor conocimiento, el artículo 48, del citado Decreto ley, prescribe:

"Se prohíbe a los turistas desarrollar actividades remuneradas. Sin embargo, el Ministerio del Interior podrá autorizarlos para que, en casos calificados, desarrollen tales actividades, por un plazo no mayor de 30 días prorrogable, por períodos iguales, hasta el término del permiso de turismo.

Al momento de conceder la autorización el Ministerio del Interior retirará la tarjeta de turismo y la reemplazará por una tarjeta especial que contendrá las menciones que establezca el reglamento.

Para su egreso del país, deberá canjear la tarjeta especial por la de turismo, previa exhibición del comprobante de pago de sus impuestos".

Esta fórmula sin duda es la que utiliza un artista que viene por ejemplo a nuestro país por un corto periodo a realizar una gira con varios conciertos en nuestro territorio.

En otro sentido, nuestro Código del Trabajo en sus artículos 19 y 20, que se encuentran bajo el capítulo "De la nacionalidad de los trabajadores", establece una serie de reglas sobre cuotas de nacionalidades dentro de un mismo empleador.

A saber:

Art. 19. El ochenta y cinco por ciento, a lo menos, de los trabajadores que sirvan a un mismo empleador será de nacionalidad chilena.

Se exceptúa de esta disposición el empleador que no ocupa más de veinticinco trabajadores. Art. 20. Para computar la proporción

1. Se tomará en cuenta el número total de trabajadores que un empleador ocupe dentro del territorio nacional y no el de las distintas sucursales separadamente;

2. Se excluirá al personal técnico especialista;

3. Se tendrá como chileno al extranjero cuyo cónyuge o sus hijos sean chilenos o que sea viudo o viuda de cónyuge chileno, y

4. Se considerará también como chilenos a los extranjeros residentes por más de cinco años en el país, sin tomarse en cuenta las ausencias accidentales".

En relación a estas normas la Dirección del Trabajo en el Dictamen Ord. N 2628/040 de 1 de julio de 2009 ha señalado que nuestro legislador laboral sólo ha limitado la contratación de trabajadores extranjeros en base a la cantidad de ellos dentro de una empresa, para lo cual ha establecido una determinada proporción y reglas a aplicarse, a fin de hacerla efectiva. Pero que sin embargo, nuestra legislación no contempla disposiciones que prohíban a los ciudadanos extranjeros ser contratados para realizar labores de cualquier índole.

No obstante lo hasta aquí expuesto, existen disposiciones que contemplan como uno de los requisitos que deben cumplir las personas que se desempeñarán dicho trabajo, que este sea de nacionalidad chilena. Así, encontramos en nuestra legislación situaciones en que se regulan ciertos trabajos que no pueden ser ejercidos por extranjero y cuya regulación no se considera atentatoria contra el principio de igualdad de trato. Por ejemplo: 
- $\quad$ El Decreto Ley No 3.607, del Ministerio del Interior, publicado en el Diario Oficial del 08-01-1981, que deroga el Decreto Ley No 194, de 1973 y establece nuevas normas sobre funcionamiento de Vigilantes Privados.

- $\quad$ El Decreto Supremo No 93, de 1985, del Ministerio de Defensa Nacional, que aprueba el Reglamento del artículo $5^{\circ}$ Bis del Decreto Ley $N^{\circ} 3.607$, y que en el inciso $2^{\circ}$ de su artículo $8^{\circ}$ establece que sólo se puede contratar para desempeñar labores de nochero, portero, rondín u otras de similar carácter a quienes reúnan, entre otros requisitos, el de ser chileno.

El Decreto Supremo No 1.773, de 1994, del Ministerio del Interior y de Defensa Nacional, que aprobó el Reglamento del Decreto Ley No 3.607, sobre funcionamiento de vigilantes privados, según se ha señalado, el que en su artículo $11^{\circ}$ también exige para el desempeño de la labor de vigilante privado la nacionalidad chilena.

Esta limitación de número de extranjeros se encuentra en discusión por el actual gobierno según lo ha expresado por la Ministra del Trabajo. Un área donde se señala que se necesitan extranjeros es la minería, asimismo, constatamos que en la agricultura cada vez menos chilenos se interesan, por ende, debería ponerse atención a estas actividades económicas y el impacto de los extranjeros que trabajan o en el futuro arriben a ella.

En cuanto a la seguridad social nuestra legislación permite que el extranjero que realiza labores en nuestro país no cotice a nuestro sistema bajo ciertas condiciones. En primer lugar, debemos afirmar que la legislación chilena, para la incorporación al sistema de seguridad social no hace diferencia entre un extranjero y un nacional, siendo obligatorio cotizar para todo trabajador dependiente. Sin embargo, se establecen exenciones para cierto tipo de trabajadores en disposiciones legales contenidas en Convenios Bilaterales de Seguridad Social y en la Ley No 18.156, publicada en el Diario Oficial el 25 de agosto de 1982, relativa a Técnicos Extranjeros.

La Ley $\mathrm{N}^{\circ} 18.156$ establece la exención de efectuar cotizaciones para los trabajadores técnicos extranjeros, como para las empresas que los contraten cumpliendo con los requisitos establecidos en su artículo $1^{\circ}$, a saber:

"Las empresas que celebren contratos de trabajo con personal técnico extranjero y este personal, estarán exentos, para los efectos de esos contratos, del cumplimiento de las leyes de previsión que rijan para los trabajadores, no estando obligados, en consecuencia, a efectuar imposiciones de ninguna naturaleza en organismos de previsión chilenos, siempre que se reúnan las siguientes condiciones:

a) Que el trabajador se encuentre afiliado a un régimen de previsión o de seguridad social fuera de Chile, cualquiera sea su naturaleza jurídica, que le otorgue prestaciones, a lo menos, en casos de enfermedad, invalidez, vejez y muerte, $y$

b) Que en el contrato de trabajo respectivo el trabajador exprese su voluntad de mantener la afiliación referida.

La exención que establece el inciso anterior no comprenderá los riesgos de accidentes del trabajo y enfermedades profesionales previstos en la ley 16.744 ".

La exención de cotizar dice relación con algunos riesgos y regímenes específicos. Así se debe igualmente cotizar para la ley de accidentes del trabajo y enfermedades profesionales. Además, como lo ha señalado la Dirección del Trabajo mediante Dictamen Ord. 1539/017, de 28 de 
marzo de 2012, los trabajadores extranjeros se encuentran obligados a efectuar cotizaciones por concepto de seguro de cesantía. Esto debido a que la exención del artículo $1^{\circ}$ de la Ley 18.156 solo ópera respecto de los riesgos enfermedad, vejez, invalidez y muerte. Teniendo entonces un alcance material limitado.

Esta ley permite además al Técnico Extranjero, en su artículo $7^{\circ}$, la posibilidad, de recuperar lo cotizado en una administradora de fondos de pensiones chilena, siempre que se cumplan los requisitos del artículo $1^{\circ}$, realizando la solicitud correspondiente.

Debemos hacer notar los posibles efectos perversos de esta normativa sobre la protección de riesgo sociales de los trabajadores. Si no están afiliados en Chile su cobertura se verá comprometida sobre todo en relación a la enfermedad. Por otra parte, esta medida puede tener por objetivo atraer trabajadores y evitarle altos costos al empleador. Sin embargo, en estas condiciones tan solo trabajadores altamente calificados y con recurso que les permitan auto protegerse pueden valerse de esta reglamentación. Entonces, cabe preguntarse por los mecanismos de protección para los trabajadores extranjeros en nuestro país con menos recursos y sobre todo por aquellos del sector informal.

\section{CONCLUSIONES}

Nuestro país posee una cobertura del extranjero en la misma forma como si se tratara de un chileno. Siendo acorde con los principios de igualdad y de no discriminación vigentes en nuestro ordenamiento, y derivados de instrumentos internacionales vigentes en Chile.

Si bien no poseemos una larga tradición en materia de acuerdos bilaterales de seguridad social poseemos un número importante. Siendo en la región uno de los países más comprometidos con la seguridad social a través de acuerdos bilaterales. Sin embargo, estos instrumentos se centran en prestaciones contributivas, y particularmente en pensiones de vejez. Que sucede entonces con las prestaciones no contributivas, por ejemplo, las pensiones solidarias o las prestaciones Auge. En el sistema de coordinación europea se contemplan mecanismos para poder entregar también una continuidad a este tipo de prestaciones. Chile y Latinoamérica están lejos de esta completa y compleja reglamentación. Aunque importantes pasos se han dado con la entrada en vigencia del Convenio Multilateral Iberoamericano de Seguridad Social que esperamos se convierta en el antecedente de un completo y complejo mecanismo de coordinación de legislaciones en nuestra región.

La legislación chilena en relación al extranjero no lo discrimina en ningún momento, tampoco en seguridad social. De hecho, discusiones, como la reforma a las visas de extranjero se están planteando en otros países de América latina, v.gr., Panamá. Este tipo de reformas sin duda lograra sincerar a lo mejor situaciones que se dan en la práctica y además formalizar y regularizar relaciones de trabajo. Pero, estas medidas así como la reglamentación expuesta están destinadas al trabajador extranjero dependiente que posee una visa de trabajo. En un país que posee una tasa de informalidad de veinticinco por ciento, sin lugar a dudas un número importante de trabajadores extranjeros laboran en la informalidad. Por tanto, si se revisa la reglamentación de extranjeros se debería revisar la protección tanto del trabajador migrante dependiente así como también la del informal, y la de sus familias.

Hemos intentado mostrar en estas páginas la importancia del trabajador migrante, revisando su protección en nuestro país. Sin embargo, no debemos olvidar que en mundo globalizado cada vez más chilenos están emigrando en busca de mejores trabajos. Entonces si reformamos la 
protección del inmigrante en nuestro país deberíamos también pensar en los chilenos emigrantes y su eventual protección por leyes chilenas.

\section{BIBLIOGRAFÍA}

Arellano Ortiz, Pablo. "La cobertura de los accidentes del trabajo y enfermedades profesionales por las normas internacionales del trabajo de la OIT", en: Revista Chilena de Derecho de Trabajo y de la Seguridad Social, vol. 2, n 3, Santiago, Chile, 2012, pp. 163-180.

Arellano Ortiz, Pablo. "La conformidad de la legislación chilena a las normas internacionales del trabajo de la OIT", en: Revista de Derecho de la Universidad Católica de la Santísima Concepción, Concepción, Chile, 2011, pp. $39-60$.

Arellano Ortiz, Pablo. "New developments in social security protection for migrants in Latin-American region". Presentado en la Conferencia "Acces Denied. Working on a new paradigm, International conference on social protection and migration" organizada por la Universidad de Amsterdam, Holanda, realizada los días 13 y 14 de marzo de 2012.

Arellano Ortiz, Pablo. "Protección de seguridad social para los migrantes: la necesidad de una intervención legal coherente". Trabajo presentado en el seminario "Seguridad social y trabajadores migrantes", realizado el día 24 de septiembre 2012 - Auditorio 4, Edificio Nahmías, U. Austral de Chile, Campus Isla Teja, organizado por la Facultad de Ciencias Jurídicas y Sociales de la Universidad Austral de Chile.

Arellano Ortiz, Pablo; Briganti, Francesco. "Europa y América Latina: encuentros y desencuentros en la búsqueda de la coordinación de los sistemas de seguridad social", en: Programa de Estudios Europeos Universidad de Concepción. Europa y América Latina. Dos caminos, ¿un destino común? Santiago, Chile: RIL Editores, 2012, pp. 125-155.

Cifuentes Lillo, Hugo. “Tratados internacionales de seguridad social: Convenios bilaterales”, en: Estudios en Homenaje al profesor William Thayer. Santiago, Chile: Sociedad Chilena de Derecho del Trabajo y Seguridad Social, 1998, pp. 16-38.

Cifuentes Lillo, Hugo; Arellano Ortiz, Pablo. "Derecho a la Seguridad Social y la protección por pensiones de vejez, invalidez y sobrevivencia en Chile", en: Rojas Miño, Irene (Coordinadora). Cincuenta años de la Sociedad Chilena de Derecho del Trabajo y de la Seguridad Social: Homenaje. Santiago, Chile: Sociedad Chilena de Derecho del Trabajo y de la Seguridad Social, AbeledoPerrot LegalPublishing, 2011, pp. 177-288.

Comisión Mundial sobre la Dimensión Social de la Globalización. Por una globalización justa: crear oportunidades para todos. Ginebra, Suiza, OIT, 2004.

Conferencia Interamericana de Seguridad Social. Informe sobre la Seguridad Social en América, 2006. Los Retos del Envejecimiento y la Discapacidad: Empleo y Aseguramiento, Convenios Internacionales de Seguridad Social. Conferencia Interamericana de Seguridad Social, edición 2006; Capítulo 4: Convenios Internacionales de Seguridad Social, pp. 89-117.

Coursier, Philippe. Conflit de lois en matière de contrat de travail. Bibliothèque de droit privé, tome 230. París, Francia: L.G.D.J, 1993.

Gumucio R, J. "Chile en el Mercosur: armonización de sistemas de Seguridad Social”, en: Revista Laboral Chilena, enero, Santiago, Chile, 1997, pp. 58-64.

Hirose, Kenichi; Nikac, Milos y Tamagno, Edward. Social security for migrant workers. A right-based approach. International Labour Organization, Decent Work Technical Support Team, and Country Office for Central and Eastern Europe-Budapest, ILO, 2011.

Humblet, M.; SiLva, R. Normas para el siglo XXI, Seguridad Social. Ginebra, Suiza, OIT, 2002.

Humeres Noguer, Héctor. Derecho del Trabajo y de la Seguridad Social. Tomo III. Derecho de la Seguridad Social. -17o edición ampliada y actualizada-. Santiago, Chile: Editorial Jurídica de Chile, 2005.

JAVILLIER, Jean- Claude; GERNIGON, Bernard (sous la direction de). Les normes internationales du travail: un patrimoine pour l'avenir. Mélanges en l'honneur de Nicolas Valticos. Geneva, Italie: Bureau International du Travail, 2004. 
Pablo Arellano Ortiz / Trabajadores migrantes y seguridad social: aproximación nacional e internacional - II parte

JiMÉNEZ, Adolfo. "Una experiencia inédita”, en: Miradas al Exterior, Revista de Información Diplomática del Ministerio de Asuntos Exteriores y de Cooperación de España, no 18, abril-junio.

Jorens, Yves (Ed). 50 years of social security coordination. Past-Present-Future, Report of the conference celebrating the 50th Anniversary of the European Coordination of Social Security. European Commission, Directorate General for Employment, Social Affairs and Equal Opportunities, Publication Office of the European Union, 2010.

Kulke, U.; Cichon, C.; Palk, K. "Changing tides: a revival of a right-based approach to social security". En: Langendonck, J. van (Ed.). The Right to Social Security. Inglaterra, Londres: Intersentia, Antwerp- Oxford, 2007.

KUPTSCH, C. «La privatisation dans la sécurité sociale: un slogan aux multiples facettes- Remarques sur le concept de privatisation en fonction du contexte», In: Scheil-adlung, X. Construire la sécurité sociale: la privatisation en question. Francia: AISS, Peter Lang SA, Bern, 2001.

LAROQUe, P. «De l'assurance à la Sécurité Sociale, l'expérience française», en: Rev. Inter. Trav. vol. LVII, nº 6, France, París, 1948, pp. 623 et. ss.

Lyon-Caen, A.; Urban, Q. (dir). Le droit du travail á l'épreuve de la globalisation. Dalloz "Thémes et commentaires", Paris, 2008.

Lyon-Caen, Gerard y Antoine. Droit social européen et international. -8e édition-. Paris, France: Précis, Dalloz, 1993.

Martínez Pizarro, J. (Editor). Migración internacional en América Latina y el Caribe. Nuevas tendencias, nuevos enfoques. Santiago, Chile: Cepal, United Nations, 2011.

Maudet-Bendahan, Marilyn. La mobilité géographique du travailleur salarié au sein de l'Union européenne. Bibliothèque de droit social, Tome 57. Paris, L.G.D.J, 2012.

Ministerio de Trabajo y Asuntos Sociales, Subsecretaria de Estado de la Seguridad Social, España. "El modelo social europeo y los proceso de reforma de la seguridad social en los países latinoamericanos". Conferencia de Ministros de Seguridad Social de Europa y Latinoamérica, Valencia, 13, 14 y 15 de mayo de 2002.

Moreau, Marie-Ange. Normes sociales, droit du travail et mondialisation-Confrontations et mutations, A droit ouvert. Dalloz-Sirey, Paris, 2006.

Novoa Fuenzalida, Patricio. Derecho de la Seguridad Social. Santiago, Chile: Editorial Jurídica de Chile, 1977.

Orт. En busca de un compromiso equitativo para los trabajadores migrantes en la economía globalizada. Informe VI, Sexto punto del orden del día Conferencia Internacional del Trabajo, 92.a reunión, 2004.

Orт. Introducción a la seguridad social. Oficina Internacional del Trabajo. Ginebra, 1984.

Oгт. Las normas internacionales del trabajo. Un enfoque global. Ginebra, 2002.

Orт. Rapport sur le travail dans le monde 2000: sécurité du revenu et protection sociale dans un monde en mutation. Commission de l'emploi et de la politique sociale. Conférence Internationale du Travail, $79^{\circ}$ session. Genève, 2000 .

Orт. Seguridad social para la justicia social y una globalización equitativa, Discusión recurrente sobre la protección social (seguridad social) en virtud de la Declaración de la OIT relativa a la justicia social para una globalización equitativa. Informe VI, Sexto punto del orden del día, Conferencia Internacional del Trabajo, 100.a reunión, 2011

Orт. Seguridad social: un nuevo consenso. Ginebra, 2002.

Orт. Trabajo Decente. Memoria del Director General, Conferencia Internacional del Trabajo, 87. a reunión. Ginebra, 1999.

Oгт. En busca de un compromiso equitativo para los trabajadores migrantes en la economía globalizada. Informe VI, Sexto punto del orden del día Conferencia Internacional del Trabajo, 92a reunión, 2004.

Orт. Introducción a la seguridad social. Oficina Internacional del Trabajo. Ginebra, 1984.

Orт. Las normas internacionales del trabajo. Un enfoque global. Ginebra, 2002. 
OIT. Rapport sur le travail dans le monde 2000: sécurité du revenu et protection sociale dans un monde en mutation. Commission de l'emploi et de la politique sociale. Conférence Internationale du Travail, $79^{\circ}$ session. Genève, 2000 .

OrT. Seguridad social para la justicia social y una globalización equitativa. Discusión recurrente sobre la protección social (seguridad social) en virtud de la Declaración de la OIT relativa a la justicia social para una globalización equitativa, Informe VI, Sexto punto del orden del día, Conferencia Internacional del Trabajo, 100.a reunión, 2011.

OrT. Seguridad social: un nuevo consenso. Ginebra, 2002.

Orт. Trabajo Decente. Memoria del Director General, Conferencia Internacional del Trabajo, 87a reunión. Ginebra, 1999.

Olivier, Marius. "Social security developments in the SADC region and future prospects for coordination". Trabajo presentado en el seminario "Seguridad social y trabajadores migrantes", realizado el día 24 de septiembre 2012. Auditorio 4, Edificio Nahmías, U. Austral de Chile, Campus Isla Teja, organizado por la Facultad de Ciencias Jurídicas y Sociales de la Universidad Austral de Chile.

Rodríguez-Piñero Bravo Ferrer, Miguel. “La OIT y los trabajadores migrantes”. En: Javillier, Jean-Claude; Gernigon, Bernard (sous la direction de). Les normes internationales du travail: un patrimoine pour l'avenir. Mélanges en l'honneur de Nicolas Valticos. Geneva, Italie: Bureau International du Travail, 2004, pp. 541-564.

Sabates-Wheeler, Rachel; Koettr, Johannes. "Protección social para los migrantes: los desafíos de la prestación en el contexto del cambio en los flujos migratorios”, en: Revista Internacional de Seguridad Social, vol. 63, 3-4/2010, p. 135.

SÁnchez-Rodas, C. (dir.). La coordinación de los sistemas de Seguridad Social. Los reglamentos 883/2004 y 987/2009. Murcia, España: Laborum, 2010.

SÁnCHEZ-Rodas, C. "El Convenio Multilateral Iberoamericano de seguridad Social”, en: Revista General de Derecho del Trabajo y de la Seguridad no 26, junio, Madrid, España, 2011.

Segura Riverro, Francisco, "Del domicilio político de los extranjero en Chile”, en: Revista de Derecho, Universidad de Concepción, no 201, año LXV, enero- junio, 1997, pp. 73-81.

SERvaIs, Jean Michel. Normes Internationales du Travail. Paris, France: L.G.D.J, 2004.

Taran, Patrick; Geronimi, Eduardo. “Globalización y migraciones laborales: importancia de la protección”, en: Perspectivas sobre las migraciones laborales. 3 S, Programa de Migraciones Internacionales, Oficina Internacional del Trabajo, Ginebra, 2003.

Valticos, Nicolas. Droit International du Travail. -2édition-. Dalloz, 1983.

VIJ, R. (ed). Globalisation and Werlfare, a critical reader. Palgrave Macmillan, 2007.

ZúNiga Urbina, Francisco, "El estatus constitucional de extranjeros", en: Revista de Derecho, Universidad de Concepción, no 203, año LXVI, enero- junio, 1998, pp. 301-330. 